Revista Brasil. Bot., V.28, n.4, p.727-733, out.-dez. 2005

\title{
Germinação de sementes de Gallesia integrifolia (Spreng.) Harms (pau-d'alho) sob diferentes condições de temperatura, luz e umidade do substrato
}

\author{
SHIRLAYNE S.U. BARROS ${ }^{1}$, ANTONIO DA SILVA² e IVOR B. AGUIAR ${ }^{3,4}$
}

(recebido: 15 de abril de 2004; aceito: 20 de outubro de 2005)

\begin{abstract}
Seed germination of Gallesia integrifolia (Spreng.) Harms under different conditions of temperature, light and substrate moisture). Gallesia integrifolia is a native tree species in Brazil, important for wood production. This work was carried out in laboratory in order to recommend the conditions for standard germination test and to predict the seed germinative behavior under natural conditions. Seeds were submitted to constant $\left(15,20,25,30\right.$ and $\left.35{ }^{\circ} \mathrm{C}\right)$ and alternating $\left(20-30{ }^{\circ} \mathrm{C}\right)$ temperature regimes, in darkness and at an eight hours photoperiod under white, red and far-red light. Vermiculite $(30 \mathrm{~g})$ was used as substrate moistened with 45,90 and $135 \mathrm{~mL}$ of distilled water. Both seed germination total percentage and speed index were evaluated. The obtained results showed that seeds are indifferent to regime temperature and that at the best temperatures tested $\left(20,25,30\right.$ and $\left.20-30{ }^{\circ} \mathrm{C}\right)$ seeds are insensitive to light. The standard germination test can be performed on vermiculite $(30 \mathrm{~g})$ moistened with 45 to $90 \mathrm{~mL}$ water volume at constant temperature (20 or $25^{\circ} \mathrm{C}$ ) and at an eight hours photoperiod under white light. Seeds germinated at the tested temperature regimes, light qualities and moisture levels, and these results suggest that under natural conditions, seeds are able to germinate either under canopy or in light gap.
\end{abstract}

Key words - ecophysiology, physiological quality, tree seed

RESUMO - (Germinação de sementes de Gallesia integrifolia (Spreng.) Harms (pau-d'alho) sob diferentes condições de temperatura, luz e umidade do substrato). Gallesia integrifolia é uma espécie arbórea nativa do Brasil, pertencente à família Phytolaccaceae e conhecida popularmente por pau-d'alho, importante como produtora de madeira. Este trabalho foi desenvolvido em laboratório, visando recomendar as condições a serem adotadas no teste padrão de germinação e prever o comportamento germinativo das sementes em condições naturais. As sementes foram submetidas às temperaturas constantes de $15,20,25,30$ e $35^{\circ} \mathrm{C}$ e alternada de $20-30{ }^{\circ} \mathrm{C}$, na ausência de luz e sob fotoperíodo de oito horas de luz dos espectros branco, vermelho e vermelho extremo. Como substrato foi utilizada vermiculita (30 g), umedecida com 45, $90 \mathrm{e}$ $135 \mathrm{~mL}$ de água destilada. Foram avaliados a porcentagem total e o índice de velocidade de germinação das sementes. Os resultados obtidos mostraram que as sementes são indiferentes ao regime de temperatura e que nas melhores temperaturas testadas $\left(20,25,30\right.$ e $\left.20-30^{\circ} \mathrm{C}\right)$, elas são insensíveis à luz. O teste padrão de germinação pode ser conduzido com $30 \mathrm{~g}$ de vermiculita umedecida com 45 a $90 \mathrm{~mL}$ de água, nas temperaturas constantes de 20 ou $25^{\circ} \mathrm{C}$, sob fotoperíodo de oito horas de luz branca. As sementes de pau-d'alho germinaram nos diferentes regimes de temperatura, qualidades de luz e níveis de umidade testados indicando que, em condições naturais, são capazes de germinar tanto sob o dossel como em clareiras.

Palavras-chave - ecofisiologia, qualidade fisiológica, semente florestal

\section{Introdução}

Gallesia integrifolia (Spreng.) Harms pertence à família Phytolaccaceae e ocorre naturalmente em vários estados brasileiros, desde o Ceará até o Paraná (Carvalho 1994). É uma espécie arbórea de grande porte, freqüente

1. Universidade Estadual Paulista, Instituto de Biociências, Caixa Postal 510, 18600-000 Botucatu, SP, Brasil.

2. Instituto Florestal, Seção de Silvicultura, Caixa Postal 1322, 01059-970 São Paulo, SP, Brasil.

3. Universidade Estadual Paulista, Faculdade de Ciências Agrárias e Veterinárias, Via de acesso Prof. Paulo Donato Castellane, 14884-900 Jaboticabal, SP, Brasil.

4._Autor para correspondência: ivor@ netsite.com.br nas florestas pluvial atlântica e estacional semidecidual (Durigan et al. 1997). Produz madeira de múltiplo uso, com cheiro característico de alho quando verde, por isso é denominada vulgarmente de pau-d'alho. A madeira perde esse cheiro quando seca e se torna durável, sendo utilizada em substituição ao pinheiro (Nogueira 1977, Carvalho 1994). Os frutos, do tipo sâmara, amadurecem de junho a outubro, quando adquirem a coloração parda; cada sâmara contém uma semente (Carvalho 1994). É praticamente impossível separar a semente do fruto (Lorenzi 1992) e para facilitar o armazenamento e a semeadura, a expansão alada da sâmara deve ser cortada (Durigan et al. 1997).

$\mathrm{O}$ fator inicial e essencial que determina a germinação de sementes viáveis e não dormentes é a 
disponibilidade de água para a embebição (Bewley \& Black 1994). Da absorção de água resulta a reidratação dos tecidos, com a conseqüente intensificação da respiração e de todas as outras atividades metabólicas, que culminam com o fornecimento de energia e nutrientes necessários para a retomada de crescimento por parte do eixo embrionário (Carvalho \& Nakagawa 2000).

A temperatura é outro fator que influencia a germinação das sementes, determinando a capacidade e a velocidade de germinação, removendo a dormência primária e/ou secundária e induzindo a dormência secundária (Bewley \& Black 1994). Sementes de muitas espécies expressam seu máximo potencial germinativo em temperaturas constantes, porém, outras o fazem sob temperaturas alternadas (Figliolia et al. 1993).

A sensibilidade das sementes à luz também varia com a espécie (Borges \& Rena 1993), mas a luz nem sempre é um fator imprescindível e limitante para a germinação (Figliolia et al. 1993). O fitocromo é o sensor fisiológico da luz nas sementes e existe em duas formas principais, que são reversíveis pela exposição a diferentes qualidades de luz. A forma ativa, que induz a germinação, é convertida da forma inativa pela exposição à luz do espectro vermelho $(\mathrm{V})$, enquanto que a luz do espectro vermelho extremo (VE) converte a forma ativa para a inativa (Vázquez-Yanes \& Orozco-Segovia 1993, Bewley \& Black 1994).

Estudos de biologia molecular do fitocromo mostraram que existe mais de um tipo desse pigmento nos tecidos vegetais (Bewley \& Black 1994), dos quais dois tem recebido maior atenção: o fitocromo A (fiA) e o fitocromo B (fiB). Perez (1995) fez referência às três classes de respostas das sementes mediadas pelo fitocromo: de fluência muito baixa, de baixa fluência e de alta irradiância. Em publicações mais recentes, como a de Casal \& Sánchez (1998), foi abordado o envolvimento do fitocromo no controle da germinação de sementes fotossensíveis. Com base nessas publicações, Takaki (2001) considerou que todas as sementes possuiriam esse pigmento, caracterizou os diferentes fitocromos presentes nas sementes (fiA, B, C, D e E) e sugeriu que o termo fotoblastismo fosse substituído pela forma do fitocromo que controla a germinação. De acordo com a proposição do autor, as sementes fotoblásticas negativas possuiriam fiA controlando a germinação através de respostas de alta irradiância; as insensíveis à luz possuiriam fiA controlando a germinação através de respostas de fluência muito baixa e as fotoblásticas positivas possuiriam fiB e pequena quantidade de fiD e fiE controlando a germinação através de respostas de baixa fluência.
O requerimento de luz pelas sementes é modificado pela temperatura (Bewley \& Black 1994) e vários artigos vêm sendo publicados envolvendo a interação entre esses dois fatores na germinação de sementes de espécies florestais nativas do Brasil. Os dados sobre a influência conjunta da umidade do substrato, temperatura e luz na germinação de sementes são mais escassos e estão restritos a resumos publicados em anais de congressos. Publicados na íntegra, foram encontrados apenas os trabalhos desenvolvidos por Souza et al. (1999) com sementes de Genipa americana L. (jenipapo) e por Silva et al. (2001) com sementes de Schinus terebinthifolius Raddi (aroeira-vermelha). A germinação das sementes de jenipapo foi estudada na ausência de luz e sob luz branca (fotoperíodo de oito horas), nas temperaturas constante de $30^{\circ} \mathrm{C}$ e alternada de $20-30^{\circ} \mathrm{C}$, em substrato umedecido com 5 a $80 \mathrm{~mL}$ de água (Souza et al. 1999). A germinação das sementes de aroeira-vermelha foi estudada nas temperaturas constantes de 20,25 e $30^{\circ} \mathrm{C}$ e alternada de $20-30{ }^{\circ} \mathrm{C}$, na ausência de luz e com fotoperíodo de oito horas sob luz dos espectros branco e vermelho extremo, em substrato umedecido com 10 a $15 \mathrm{~mL}$ de água (Silva et al. 2001).

Sementes de Gallesia integrifolia (pau-d'alho), neste trabalho, foram submetidas a diferentes temperaturas, qualidades de luz e níveis de umidade do substrato, em laboratório, com os objetivos de recomendar as condições a serem adotadas no teste padrão de germinação e prever o comportamento germinativo das sementes em condições naturais.

\section{Material e métodos}

Sâmaras de pau-d'alho, de coloração parda, foram colhidas de cinco árvores matrizes localizadas na Estação Experimental de Santa Rita do Passa Quatro, pertencente ao Instituto Florestal do Estado de São Paulo, em agosto de 1998. Esta estação está situada a $21^{\circ} 40^{\prime}$ S e $47^{\circ} 30^{\prime} \mathrm{W}$, a $715 \mathrm{~m}$ de altitude; de acordo com a classificação climática de Köppen o clima é Cwa, ou seja, quente de inverno seco (Ventura et al. 1965/1966). Após secagem ao sol por dois dias, as sâmaras foram levadas para o laboratório de sementes do Instituto Florestal, em São Paulo, onde a expansão alada foi cortada e a estrutura resultante foi considerada semente.

As sementes foram acondicionadas em embalagem de natureza semipermeável (saco de náilon-polietileno) e armazenadas em câmara fria $\left(5^{\circ} \mathrm{C}\right.$ e $90 \%$ UR). Os testes de germinação foram instalados em maio de 1999, com quatro repetições de 25 sementes previamente desinfectadas com hipoclorito de sódio a $4 \%$ por cinco minutos e colocadas em caixas plásticas de $11 \times 11 \times 4 \mathrm{~cm}$ (gerboxes), com tampa, sobre o substrato umedecido. 
Foram utilizados, como substrato, $30 \mathrm{~g}$ de vermiculita do tipo 2, com diâmetro variando de 0,71 a 3,36 mm, umedecidos com 45, 90 e $135 \mathrm{~mL}$ de água destilada, sem posterior reumedecimento. Os testes de germinação foram conduzidos em germinadores de câmara regulados para as temperaturas constantes de $15,20,25,30$ e $35^{\circ} \mathrm{C}$ e alternada de $20-30{ }^{\circ} \mathrm{C}\left(16 \mathrm{~h}\right.$ a $20^{\circ} \mathrm{C}$ e $8 \mathrm{~h}$ a $30^{\circ} \mathrm{C}$ por dia $)$. Para cada temperatura e nível de umidade do substrato, as sementes foram submetidas à ausência de luz e à presença de luz dos espectros branco, vermelho e vermelho extremo.

Gerboxes transparentes foram utilizados no tratamento referente à luz branca, sob quatro lâmpadas fluorescentes de $20 \mathrm{~W}$ (irradiância de aproximadamente $20 \mu \mathrm{mol} . \mathrm{m}^{-2} \cdot \mathrm{s}^{-1}$, segundo Valio \& Scarpa 2001), e no tratamento referente ao escuro (ausência de luz) foram utilizados gerboxes de coloração preta envoltos em papel alumínio. Para a obtenção da luz dos espectros vermelho e vermelho extremo, foram confeccionados filtros coloridos que envolveram os gerboxes transparentes, seguindo o procedimento adotado por Silva et al. (1997). O filtro correspondente ao espectro vermelho foi constituído de duas folhas de papel celofane vermelho, sob quatro lâmpadas fluorescentes de $20 \mathrm{~W}$, e o correspondente ao espectro vermelho extremo, de três folhas de papel celofane azul mais duas folhas de papel celofane vermelho, sob quatro lâmpadas incandescentes de $25 \mathrm{~W}$. Esses conjuntos proporcionam, respectivamente, razão V/VE de 0,6 e de 0,1 , de acordo com Valio \& Scarpa (2001).

Foi adotado o fotoperíodo de oito horas, nos tratamentos em que as sementes foram expostas à luz; no caso da temperatura alternada, o período luminoso correspondeu àquele sob temperatura mais elevada. Para o tratamento referente à luz branca, os testes de germinação foram preparados e avaliados sob iluminação normal de laboratório, enquanto que para as demais condições de luz, os testes foram preparados e avaliados em câmara iluminada com duas lâmpadas fluorescentes $15 \mathrm{w}$ envolvidas por duas folhas de papel celofane verde (espectro de 0,02 $\mu \mathrm{W} . \mathrm{cm}^{-2} . \mathrm{nm}$, conforme Lopes \& Soares 2003).

Foram consideradas germinadas as sementes que emitiram a raiz primária. As contagens foram feitas diariamente, a partir do início da germinação (oito dias), e encerradas 38 dias após a instalação dos testes. A qualidade fisiológica das sementes foi representada pela porcentagem total de germinação, obtida no encerramento dos testes, e pela velocidade de germinação. A velocidade de germinação foi expressa pelo índice proposto por Maguire (1962), obtido pelo somatório do número de sementes germinadas em cada contagem dividido pelo número de dias correspondente à respectiva contagem.

$\mathrm{O}$ experimento foi instalado seguindo o delineamento inteiramente casualizado e as análises de variância foram efetuadas sob o esquema fatorial $6 \times 4 \times 3$ (seis temperaturas, quatro qualidades de luz e três níveis de umidade do substrato). Para fins de análise estatística, os dados de porcentagem foram transformados em arco seno, mas nas tabelas estão apresentados sem transformação. As médias foram comparadas pelo teste de Tukey, em nível de 5\% de probabilidade (Pimentel-Gomes \& Garcia 2002).

\section{Resultados e Discussão}

As análises de variância revelaram efeito significativo dos três fatores testados (temperatura, luz e umidade do substrato), tanto para a porcentagem quanto para a velocidade de germinação das sementes de pau-d'alho (tabela 1). As interações também foram significativas, com exceção daquelas envolvendo luz e umidade do substrato, para a porcentagem de germinação, e temperatura e luz para a velocidade de germinação. Em sementes de aroeira-vermelha, todas as interações duplas envolvendo esses três fatores foram significativas, para a porcentagem e a velocidade de germinação, como verificaram Silva et al. (2001).

As sementes de pau-d'alho germinaram em todos os tratamentos (tabelas 2,3), revelando capacidade para germinar em diferentes condições ambientais. Maiores porcentagem e velocidade de germinação foram obtidas nas temperaturas constantes de 20,25 e $30^{\circ} \mathrm{C}$ e alternada de $20-30^{\circ} \mathrm{C}$ (tabelas 2-4), concordando com a afirmação de Borges \& Rena (1993) de que a faixa de 20 a $30^{\circ} \mathrm{C}$ mostra-se adequada para a germinação de grande número

Tabela 1. Valores de F resultantes das análises estatísticas referentes à porcentagem $(\% \mathrm{G})$ e índice de velocidade (IVG) de germinação das sementes de Gallesia integrifolia (pau-d'alho) submetidas a diferentes temperaturas (T), qualidades de luz (L) e níveis de umidade do substrato (U). ns $=$ não significativo $(\mathrm{p}>0,05) ; *$ significativo $(\mathrm{p}<0,05)$; $* *$ significativo $(\mathrm{p}<0,01)$.

Table 1. F values from statistic analysis concerning to germination percentage $(\% \mathrm{G})$ and speed index (IVG) of Gallesia integrifolia seeds submitted to different temperatures $(\mathrm{T})$, light qualities $(\mathrm{L})$ and levels of moisture substrate $(\mathrm{U}) . \mathrm{ns}=$ not significant $(\mathrm{p}>0,05) ; *=$ significant $(\mathrm{p}<0,05) ; * *=$ significant $(\mathrm{p}<0,01)$.

\begin{tabular}{lcc}
\hline Causa de variação & $\% \mathrm{G}$ & IVG \\
\hline Temperatura (T) & $27,88^{* *}$ & $77,41^{* *}$ \\
Qualidade de luz (L) & $5,23^{* *}$ & $8,19^{* *}$ \\
Umidade do substrato (U) & $108,46^{* *}$ & $129,58^{* *}$ \\
Interação $(\mathrm{T} \times \mathrm{L})$ & $2,11^{*}$ & $1,11^{\text {ns }}$ \\
Interação $(\mathrm{T} \times \mathrm{U})$ & $7,14^{* *}$ & $7,93^{* *}$ \\
Interação $(\mathrm{L} \times \mathrm{U})$ & $2,09^{\text {ns }}$ & $3,70^{* *}$ \\
Coeficiente de variação $(\%)$ & 17,23 & 22,91 \\
\hline
\end{tabular}


Tabela 2. Porcentagem de germinação das sementes de Gallesia integrifolia (pau-d'alho) submetidas a diferentes temperaturas e qualidades de luz. Valores médios dos três níveis de umidade testados. Médias seguidas da mesma letra, minúscula na coluna e maiúscula na linha, não diferem entre si $(\mathrm{p}>0,05)$.

Table 2. Germination percentage of Gallesia integrifolia seeds submitted to different temperatures and light qualities. Mean values from the three moisture levels tested. Means followed by the same letter, small for each column and capital for each line, are not significantily different $(p>0,05)$.

\begin{tabular}{ccccc}
\hline \multirow{2}{*}{$\begin{array}{c}\text { Temperatura } \\
\left({ }^{\circ} \mathrm{C}\right)\end{array}$} & Ausência & \multicolumn{3}{c}{ Espectro de luz } \\
\cline { 3 - 5 } & de luz & Branco & Vermelho & Vermelho extremo \\
\hline 15 & $52 \mathrm{bB}$ & $51 \mathrm{cB}$ & $64 \mathrm{bcAB}$ & $76 \mathrm{abA}$ \\
20 & $85 \mathrm{aA}$ & $78 \mathrm{aA}$ & $84 \mathrm{aA}$ & $82 \mathrm{aA}$ \\
25 & $81 \mathrm{aA}$ & $79 \mathrm{aA}$ & $81 \mathrm{aA}$ & $79 \mathrm{abA}$ \\
30 & $74 \mathrm{aA}$ & $62 \mathrm{bcA}$ & $75 \mathrm{abA}$ & $72 \mathrm{abA}$ \\
35 & $48 \mathrm{bB}$ & $52 \mathrm{cAB}$ & $53 \mathrm{cAB}$ & $62 \mathrm{bA}$ \\
$20-30$ & $74 \mathrm{aA}$ & $68 \mathrm{abA}$ & $66 \mathrm{bcA}$ & $76 \mathrm{abA}$ \\
\hline
\end{tabular}

de espécies subtropicais e tropicais. Embora todas as sementes de uma espécie possam germinar em ampla faixa de temperatura, a máxima porcentagem de germinação no menor período de tempo ocorre na faixa ótima (Bewley \& Black 1994).

Não houve diferença significativa entre as diferentes qualidades de luz testadas, para a porcentagem de germinação, quando os testes foram conduzidos nas temperaturas ótimas (tabela 2). Resultados semelhantes foram obtidos por Silva et al. (1997) com sementes de Esenbeckia leiocarpa Engl. (guarantã), testando as mesmas qualidades de luz, e por Silva et al. (2002) testando a germinação de sementes de Myracrodruon urundeuva Allemão (aroeira) na ausência de luz e na presença de luz branca. Conforme Grose \& Zimmer (1957) apud Borges \& Rena (1993), sementes de Eucalyptus camaldulensis Dehn. necessitaram de luz para a germinação, mas essa necessidade foi reduzida quando a temperatura se aproximou do nível ótimo. Sementes de Miconia cinnamomifolia (Dc.) Naud (micônia), entretanto, necessitaram de luz para germinar, mesmo na temperatura constante ótima (Lopes \& Soares 2003), mas é importante ressaltar que os autores não testaram o efeito da luz no regime de temperatura alternada, que também conduziu a bom comportamento germinativo, e que a alternância da temperatura pode substituir a necessidade de luz para a germinação, como salientaram Bewley \& Black (1994).

Considerável porcentagem de germinação foi constatada mesmo nas temperaturas menos adequadas $\left(15\right.$ e $35^{\circ} \mathrm{C}$ ), em todas as qualidades de luz testadas (tabela 2). Esse comportamento, aliado à interação não significativa verificada entre luz e temperatura, para a velocidade de germinação (tabela 1), permite classificar as sementes de pau-d'alho como indiferentes ou insensíveis à luz. A germinação em diferentes condições de luz pode ser devida ao fato da quantidade de fitocromo na forma ativa existente nas sementes ser suficiente para induzir o processo germinativo (Bewley \& Black 1994). Segundo a proposição de Takaki (2001), sementes insensíveis à luz possuiriam fiA controlando a germinação através de respostas de fluência muito baixa.

Melhor comportamento germinativo das sementes de pau-d'alho, considerando as três temperaturas constantes mais adequadas, foi constatado a 20 e $25^{\circ} \mathrm{C}$ (tabela 2). A $30^{\circ} \mathrm{C}$ a germinação foi ligeiramente inferior, em todas as condições de luz (tabela 2) e em substratos mais úmidos (tabela 3). Levando em conta que a espécie ocorre até na região nordeste brasileira (Carvalho 1994), é necessário verificar se as sementes procedentes de regiões mais quentes apresentam melhor comportamento germinativo em temperaturas mais elevadas.

Não foi constatada diferença significativa, na maioria dos tratamentos, entre os resultados obtidos na temperatura alternada de $20-30{ }^{\circ} \mathrm{C}$ e os obtidos nas temperaturas constantes de 20,25 e $30^{\circ} \mathrm{C}$, indicando que as sementes de pau-d'alho podem ser consideradas indiferentes a esses regimes de temperatura. Comparando com os resultados obtidos a 20 e $25^{\circ} \mathrm{C}$, em todos os tratamentos a germinação foi inferior na temperatura alternada, contudo, apenas sob luz vermelha e em substrato muito úmido $(135 \mathrm{~mL})$ a diferença foi significativa (tabelas 2-4).

Sementes de guarantã também foram indiferentes ao regime de temperatura (temperaturas constantes de 25 e $30^{\circ} \mathrm{C}$ e alternada de $25-30^{\circ} \mathrm{C}$ ), para a porcentagem 
Tabela 3. Porcentagem de germinação das sementes de Gallesia integrifolia (pau-d'alho) submetidas a diferentes temperaturas e níveis de umidade do substrato. Valores médios das quatro qualidades de luz testadas. Médias seguidas da mesma letra, minúscula na coluna e maiúscula na linha, não diferem entre si ( $p>0,05)$.

Table 3. Germination percentage of Gallesia integrifolia seeds submitted to different temperatures and levels of moisture substrate. Mean values from the four light qualities tested. Means followed by the same letter, small for each column and capital for each line, are not significantily different $(p>0,05)$.

\begin{tabular}{clll}
\hline $\begin{array}{c}\text { Temperatura } \\
\left({ }^{(} \mathrm{C}\right)\end{array}$ & \multicolumn{3}{c}{ Umidade do substrato } \\
\cline { 2 - 4 } & $45 \mathrm{~mL}$ & $90 \mathrm{~mL}$ & $135 \mathrm{~mL}$ \\
\hline 15 & $58 \mathrm{cB}$ & $74 \mathrm{aA}$ & $51 \mathrm{bB}$ \\
20 & $92 \mathrm{aA}$ & $84 \mathrm{aB}$ & $71 \mathrm{aC}$ \\
25 & $89 \mathrm{abA}$ & $82 \mathrm{aA}$ & $69 \mathrm{aB}$ \\
30 & $86 \mathrm{abA}$ & $71 \mathrm{abB}$ & $56 \mathrm{abC}$ \\
35 & $82 \mathrm{bA}$ & $58 \mathrm{bB}$ & $22 \mathrm{cC}$ \\
$20-30$ & $85 \mathrm{abA}$ & $79 \mathrm{aA}$ & $49 \mathrm{bB}$ \\
\hline
\end{tabular}

e a velocidade de germinação, quando submetidas à luz dos espectros branco, vermelho e vermelho extremo (Silva et al. 1997). A germinação das sementes de jenipapo não foi afetada pelo regime de temperatura, quanto à capacidade germinativa, porém, foi mais lenta na temperatura alternada, tanto na presença como na ausência de luz (Souza et al. 1999). Para sementes de aroeira-vermelha, considerando as temperaturas constante de $25^{\circ} \mathrm{C}$ e alternada de $20-30^{\circ} \mathrm{C}$, Silva et al. (2001) não constataram efeito significativo do regime de temperatura, na presença e ausência de luz, tanto para a porcentagem como para a velocidade de germinação. Resultados semelhantes foram constatados por Silva et al. (2002) com sementes de aroeira, considerando as temperaturas constantes de $20{ }^{\circ} \mathrm{C}$ e alternada de $20-30{ }^{\circ} \mathrm{C}$. Em experimento conduzido apenas sob luz branca, considerando os resultados de porcentagem e velocidade de germinação obtidos nas melhores temperaturas $\left(30{ }^{\circ} \mathrm{C}, 25-30{ }^{\circ} \mathrm{C}, 25-35{ }^{\circ} \mathrm{C}\right.$ e $30-35^{\circ} \mathrm{C}$ ), Lopes \& Soares (2003) também observaram que as sementes de micônia foram indiferentes ao regime de temperatura.

Abaixo e acima da faixa mais adequada, ou seja, nas temperaturas de 15 e $35^{\circ} \mathrm{C}$, a germinação das sementes de pau-d'alho ocorreu com menor velocidade, principalmente a $15{ }^{\circ} \mathrm{C}$ (tabela 4), obtendo-se no final do período de duração dos testes menor porcentagem de sementes germinadas (tabelas 2, 3). Segundo Bewley
Tabela 4. Índice de velocidade de germinação das sementes de Gallesia integrifolia (pau-d'alho) submetidas a diferentes temperaturas e níveis de umidade do substrato. Valores médios das quatro qualidades de luz testadas. Médias seguidas da mesma letra, minúscula na coluna e maiúscula na linha, não diferem entre si $(\mathrm{p}>0,05)$.

Table 4. Germination speed index of Gallesia integrifolia seeds submitted to different temperatures and levels of moisture substrate. Mean values from the four light qualities tested. Means followed by the same letter, small for each column and capital for each line, are not significantily different $(\mathrm{p}>0,05)$.

\begin{tabular}{clll}
\hline $\begin{array}{c}\text { Temperatura } \\
\left({ }^{\circ} \mathrm{C}\right)\end{array}$ & \multicolumn{3}{c}{ Umidade do substrato } \\
\cline { 2 - 4 } & $45 \mathrm{~mL}$ & $90 \mathrm{~mL}$ & $135 \mathrm{~mL}$ \\
\hline 15 & $0,6 \mathrm{bAB}$ & $0,8 \mathrm{cA}$ & $0,5 \mathrm{cB}$ \\
20 & $1,8 \mathrm{aA}$ & $1,8 \mathrm{aA}$ & $1,4 \mathrm{aB}$ \\
25 & $1,8 \mathrm{aA}$ & $1,8 \mathrm{aA}$ & $1,2 \mathrm{aB}$ \\
30 & $1,9 \mathrm{aA}$ & $1,5 \mathrm{abB}$ & $1,1 \mathrm{abC}$ \\
35 & $1,6 \mathrm{aA}$ & $1,4 \mathrm{bA}$ & $0,3 \mathrm{cB}$ \\
$20-30$ & $1,6 \mathrm{aA}$ & $1,6 \mathrm{abA}$ & $0,9 \mathrm{bB}$ \\
\hline
\end{tabular}

\& Black (1994) e Carvalho \& Nakagawa (2000), temperaturas abaixo da ótima reduzem a velocidade do processo germinativo e acima da ótima desorganizam esse processo, conduzindo, nos dois casos, à redução no total de sementes germinadas.

O excesso de umidade prejudicou a germinação das sementes de pau-d'alho, impedindo a penetração de oxigênio e reduzindo o processo metabólico, como salientaram Borges \& Rena (1993). Menores valores de porcentagem (tabela 3) e velocidade (tabelas 4, 5) de germinação foram obtidos com $135 \mathrm{~mL}$ de água. De acordo com Amaral (1986), nos testes de germinação o substrato deve permanecer suficientemente umedecido durante o período de duração do teste, mas nunca envolvendo as sementes com uma película de água, que pode restringir a respiração das sementes. A quantidade de água necessária para a embebição das sementes geralmente é pequena e a difusão da água ocorre em um gradiente de energia no sentido de alto para baixo potencial hídrico (Bewley \& Black 1994).

As sementes de pau-d'alho germinaram melhor em substratos menos úmidos, principalmente com $45 \mathrm{~mL}$ de água. Apenas na temperatura de $15^{\circ} \mathrm{C}$, a porcentagem (tabela 3 ) e a velocidade (tabela 4) de germinação obtidas com $90 \mathrm{~mL}$ de água foram superiores às obtidas com $45 \mathrm{~mL}$ de água. Nas demais temperaturas, a porcentagem de germinação foi maior com $45 \mathrm{~mL}$ do que com $90 \mathrm{~mL}$ de água, de maneira significativa nas temperaturas de 
Tabela 5. Índice de velocidade de germinação das sementes de Gallesia integrifolia (pau-d'alho) submetidas a diferentes qualidades de luz e níveis de umidade do substrato. Valores médios das seis temperaturas testadas. Médias seguidas da mesma letra, minúscula na coluna e maiúscula na linha, não diferem entre si $(\mathrm{p}>0,05)$.

Table 5. Germination speed index of Gallesia integrifolia seeds submitted to different light qualities and levels of moisture substrate. Mean values from the six temperatures tested. Means followed by the same letter, small for each column and capital for each line, are not significantily different $(\mathrm{p}>0,05)$.

\begin{tabular}{llcc}
\hline Espectro de luz & \multicolumn{3}{c}{ Umidade do substrato } \\
\cline { 2 - 4 } & $45 \mathrm{~mL}$ & $90 \mathrm{~mL}$ & $135 \mathrm{~mL}$ \\
\hline Ausência de luz & $1,5 \mathrm{aA}$ & $1,5 \mathrm{aA}$ & $1,1 \mathrm{aB}$ \\
Branco & $1,5 \mathrm{aA}$ & $1,3 \mathrm{aA}$ & $0,6 \mathrm{bB}$ \\
Vermelho & $1,6 \mathrm{aA}$ & $1,6 \mathrm{aA}$ & $0,9 \mathrm{aB}$ \\
Vermelho extremo & $1,5 \mathrm{aA}$ & $1,5 \mathrm{aA}$ & $1,1 \mathrm{aB}$ \\
\hline
\end{tabular}

20,30 e $35^{\circ} \mathrm{C}$, e não significativa nas temperaturas de $25^{\circ} \mathrm{C}$ e $20-30{ }^{\circ} \mathrm{C}$ (tabela 3 ). Quanto à velocidade de germinação, apenas a $30^{\circ} \mathrm{C}$ (tabela 4) e sob luz branca (tabela 5), os valores obtidos com $45 \mathrm{~mL}$ de água foram superiores aos obtidos com $90 \mathrm{~mL}$ de água.

Outras espécies se comportaram de forma diferenciada quanto ao umedecimento do substrato. A porcentagem e a velocidade de germinação das sementes de Myroxylon balsamum (L.) Harms (bálsamo) não foram afetadas pelos níveis de umidade testados $(25,32$ e $40 \mathrm{~mL}$ de água), como verificaram Borges et al. (1980). Por outro lado, Souza et al. (1999) constataram que a capacidade de germinação das sementes de jenipapo não foi afetada pelo volume de água adicionado ao substrato, contudo, no maior volume adotado $(80 \mathrm{~mL})$, houve redução significativa na velocidade de germinação e na emergência de plântulas, o que não ocorreu com $70 \mathrm{~mL}$ de água. Sementes de aroeira-vermelha foram mais sensíveis à umidade do substrato, pois melhor comportamento germinativo foi constatado em substrato considerado pelos autores (Silva et al. 2001) úmido $(10 \mathrm{~mL})$ e muito úmido $(12,5 \mathrm{~mL})$ do que em substrato encharcado $(15 \mathrm{~mL})$.

A vermiculita mostrou-se adequada como substrato, tendo sido selecionada para uso no presente trabalho por apresentar elevada capacidade de retenção de água e ser recomendada para espécies mais sensíveis ao ressecamento (Figliolia et al. 1993, Figliolia \& PinaRodrigues 1995). A espécie estudada ocorre também em solos úmidos, como os de baixadas e de margens de rios
(Nogueira 1977, Lorenzi 1992, Carvalho 1994, Durigan et al. 1997) e o uso de outro material, como substrato, poderia exigir reumedecimento.

O substrato a ser utilizado no teste padrão de germinação de sementes de pau-d'alho, portanto, pode ser a vermiculita, devendo ser umedecida com 45 a $90 \mathrm{~mL}$ de água, como mostram os resultados apresentados nas tabelas 3, 4 e 5. É mais conveniente conduzir o teste com fotoperíodo de oito horas sob luz branca (lâmpadas fluorescentes de germinadores de câmara convencionais), embora as sementes não necessitem de luz para adequada germinação (tabelas 2, 5). Essa condição de luz é comum nos laboratórios de sementes, onde são conduzidos testes de rotina, e facilita as avaliações, que não precisam ser efetuadas sob luz verde de segurança. Nesse caso, devem ser adotadas as temperaturas constantes de 20 ou $25^{\circ} \mathrm{C}$, que proporcionaram bom desempenho germinativo (tabelas 2, 4).

Os resultados obtidos em laboratório podem ser utilizados para prever o comportamento germinativo das sementes em condições naturais. A temperatura do solo, em locais cobertos pela vegetação, tende a ser constante ao longo do dia e a luz filtrada pela vegetação tem baixo valor de V/VE; em locais descobertos, entretanto, a temperatura do solo pode flutuar drasticamente e a luz solar que chega ao solo tem alto valor de V/VE (VázquezYanes \& Orozco-Segovia 1984, Bewley \& Black 1994). A umidade do solo, conseqüentemente, é maior sob o dossel do que em clareiras. Assim, em condições naturais, as sementes de pau-d'alho são capazes de germinar nesses dois ambientes, uma vez que, em laboratório, apresentaram considerável germinação tanto quando submetidas à luz do espectro vermelho extremo, temperatura constante e substrato mais úmido, condições predominantes sob o dossel, como à luz vermelha, temperatura alternada e substrato menos úmido, condições predominantes nas clareiras.

Agradecimentos - À Profa. Dra. Valderez Pontes Matos, do Departamento de Agronomia da Universidade Federal Rural de Pernambuco, pela supervisão do estágio realizado pelo primeiro autor; ao $\mathrm{CNPq}$, pela bolsa de produtividade em pesquisa concedida ao terceiro autor.

\section{Referências bibliográficas}

AMARAL, D.M.I. 1986. Padronização de testes em laboratório com sementes florestais. In Anais do I Simpósio Brasileiro sobre Tecnologia de Sementes Florestais (I.B. Aguiar, coord.). Abrates, Brasília, p.267-283. 
BEWLEY, J.D. \& BLACK, M. 1994. Seeds: physiology of development and germination. $2^{\text {nd }}$ ed. Plenum Press, New York.

BORGES, E.E.L., REGAZI, A.J., BORGES, R.C.G. \& CANDIDO, J.F. 1980. Efeitos da temperatura e da umidade na germinação de sementes de bálsamo. Revista Brasileira de Sementes 2:33-37.

BORGES, E.E.L. \& RENA, A.B. 1993. Germinação de sementes. In Sementes florestais tropicais (I.B. Aguiar, F.C.M. Piña-Rodrigues \& M.B. Figliolia, coords.). Abrates, Brasília, p.83-135.

CARVALHO, N.M. \& NAKAGAWA, J. 2000. Sementes: ciência, tecnologia e produção. $4^{\mathrm{a}}$ ed. Funep, Jaboticabal.

CARVALHO, P.E.R. 1994. Espécies florestais brasileiras: recomendações silviculturais, potencialidades e uso da madeira. Embrapa/Cnpf, Colombo.

CASAL, J.J. \& SÁNCHEZ, R.A. 1998. Phytochromes and seed germination. Seed Science Research 8:317-329.

DURIGAN, G., FIGLIOLIA, M.B., KAWABATA, M., GARRIDO, M.A.O. \& BAITELLO, J.B. 1997. Sementes e mudas de árvores tropicais. Instituto Florestal, São Paulo.

FIGLIOLA, M.B., OLIVEIRA, E.C. \& PIÑA-RODRIGUES, F.C.M. 1993. Análise de sementes. In Sementes florestais tropicais (I.B. Aguiar, F.C.M. Piña-Rodrigues \& M.B. Figliolia, coords.). Abrates, Brasília, p.137-174.

FIGLIOLIA, M.B. \& PIÑA-RODRIGUES, F.C.M. 1995. Considerações práticas sobre o teste de germinação. IF Série Registros 14:45-60.

LOPES, J.C. \& SOARES, A.S. 2003. Germinação de sementes de Miconia cinnamomifolia (Dc.) Naud. Brasil Florestal 75:31-38.

LORENZI, H. 1992. Árvores brasileiras: manual de identificação e cultivo de plantas arbóreas nativas do Brasil. Editora Plantarum, Nova Odessa.

MAGUIRE, J.D. 1962. Speed of germination-aid selection and evaluation for seedling emergence and vigor. Crop Science 2:176-177.

NOGUEIRA, J.C.B. 1977. Reflorestamento heterogêneo com essências indígenas. Boletim Técnico 24. Instituto Florestal, São Paulo.
PEREZ, S.C.J.G.A. 1995. Ecofisiologia de sementes florestais. Informativo Abrates 5:13-30.

PIMENTEL-GOMES, F. \& GARCIA, C.H. 2002. Estatística aplicada a experimentos agronômicos e florestais: exposição com exemplos e orientações para uso de aplicativos. Fealq, Piracicaba.

SILVA, A., CASTELLANI, E.D., AGUIAR, I.B., SADER, R. \& RODRIGUES, T.J.D. 1997. Interação de luz e temperatura na germinação de sementes de Esenbeckia leiocarpa Engl. (guarantã). Revista do Instituto Florestal 9:57-64.

SILVA, L.M.M., RODRIGUES, T.J.D. \& AGUIAR, I.B. 2002. Efeito da luz e da temperatura na germinação de sementes de aroeira (Myracrodruon urundeuva Allemão). Revista Árvore 26:691-697.

SILVA, M.C.C., NAKAGAWA, J. \& FIGLIOLIA, M.B. 2001. Influência da temperatura, da luz e do teor de água na germinação de sementes de Schinus terebinthifolius Raddi - Anacardiaceae (aroeira-vermelha). Revista do Instituto Florestal 13:135-146.

SOUZA, A.F., ANDRADE, A.C.S., RAMOS, F.N. \& LOUREIRO, M.B. 1999. Ecophysiology and morphology of seed germination of the neotropical lowland tree Genipa americana (Rubiaceae). Journal of Tropical Ecology 15:667-680.

TAKAKI, M. 2001. New proposal of classification of seeds based on forms of phytochrome instead of photoblastism. Revista Brasileira de Fisiologia Vegetal 13:103-107.

VALIO, I.F.M. \& SCARPA, F.M. 2001. Germination of seeds of tropical pioneer species under controlled and natural conditions. Revista Brasileira de Botânica 24:79-84.

VÁZQUEZ-YANES, C. \& OROZCO-SEGOVIA, A. 1984. Fisiología ecológica de las semillas de árboles de la selva tropical: un reflejo de su ambiente. Ciencia 35:191-201.

VÁZQUEZ-YANES, C. \& OROZCO-SEGOVIA, A. 1993. Patterns of seed longevity and germination in the tropical rainforest. Annual Review of Ecology and Systematics 24:69-87.

VENTURA, A., BERENGUT, G. \& VICTOR, M.A.M. 1965/ 1966. Características edafo-climáticas das dependências do Serviço Florestal do Estado de São Paulo. Silvicultura em São Paulo 4/5:57-140. 